PNNL-13256

\title{
Data Quality Objectives for Moisture Measurement in Stabilized Special Nuclear Material
}

Dennis R. Weier

Brent A. Pulsipher

Kurt L. Silvers

May, 2000

Prepared for the U.S. Department of Energy under contract DE-AC06-76RLO 1830

Pacific Northwest National Laboratory

Richland, Washington 99352 


\section{DISCLAIMER}

This report was.prepared as an account of work sponsored by an agency of the United States Government. Neither the United States Government nor any agency thereof, nor any of their employees, make any warranty, express or implied, or assumes any legal liability or responsibility for the accuracy, completeness, or usefulness of any information, apparatus, product, or process disclosed, or represents that its use would not infringe privately owned rights. Reference herein to any specific commercial product, process, or service by trade name, trademark, manufacturer, or otherwise does not necessarily constitute or imply its endorsement, recommendation, or favoring by the United States Government or any agency thereof. The views and opinions of authors expressed herein do not necessarily state or reflect those of the United States Government or any agency thereof. 


\section{DISCLAIMER}

Portions of this document may be illegible in electronic image products. Images are produced from the best available original document. 


\title{
Data Quality Objectives for Moisture Measurement in Stabilized Special Nuclear Material
}

\begin{abstract}
Data Quality Objectives methodology is applied to Loss-on-Ignition (LOI) moisture content testing for stabilized nuclear materials. This work was performed by Pacific Northwest National Laboratory in support of the Plutonium Finishing Plant (PFP) / Fluor Hanford, Inc.

Historical results on LOI test results for two material types, oxide and sludge, are used to estimate within container variability. This variability estimate is then used in formulating the two recommended acceptance criteria for containers of material. The criteria which follow are proposed to replace the current criterion, which requires recycle if either of two container LOI measurements exceed 0.5 wt\%, the DOE Standard 3013-99 threshold value.
\end{abstract}

1. The $95 \%$ upper confidence limit (UCL) for the true mean underlying moisture content in the container material should be less than $0.5 \mathrm{wt} \%$.

2. The difference between the two LOI measurements per container should not exceed their expected $95^{\text {th }}$ percentile relative to the estimated variability.

Containers not meeting the first criterion, or those that generate in any negative LOI result, require material recycle. Containers not meeting the second criteria require review of the. measurement results, potentially leading to resampling and retesting.

Data from Los Alamos National Laboratory studies on moisture testing are obtained and analyzed. The performance of Supercritical Fluid Extraction (SFE), which will soon be implemented at the PFP, is described for several material types. This information will be used to establish initial acceptance criteria when SFE comes on line. 


\section{Data Quality Objectives for Moisture Measurement in Stabilized Special Nuclear Material}

\section{EXECUTIVE SUMMARY}

This report is the final deliverable as agreed upon in the statement of work with Contract Release Title "DQOs for Moisture Measurement in Stabilized SNM". In this activity the Pacific Northwest National Laboratory (PNNL) Statistics Group supports Fluor-Hanford, Inc. (FD) / Plutonium Finishing Plant (PFP). The purpose is to review sampling and analysis approaches to moisture content testing of stabilized nuclear material and to characterize the performance of these approaches using the Data Quality Objectives (DQO) methodology. Potential improvements to the approaches will thereby be identified.

Recommendations are made for two criteria for Loss-on-Ignition (LOI) measurements:

1. Replacing the current moisture content testing criteria (recycle container material if either of the two LOI measurements per container exceeds $0.5 \mathrm{wt} \%$ ) with the application of a $95 \%$ upper confidence limit (UCL) decision criteria in order to identify those containers that require recycle.

2. Flagging containers whose two measurements are "too different" from each other and thus requiring some type of verification review of measurement results, potentially leading to resampling and retesting, but not recycle unless the additional evaluation so warrants.

The current practice of generating two LOI measurements per container is retained, since PFP management considers the resulting protection against decision errors to be sufficient. As process changes are implemented, such as installing a new material blender, testing using SFE, or reducing numbers of containers sampled, this measurement rate should be re-evaluated. Historical LOI data are available for oxide and sludge material types. Analysis showed the variability within containers to be approximately the same. Thus the same criteria can be used for either material type. New material types, and the conversion to super-critical fluid extraction (SFE) testing, will require similar investigation to determine what modifications to the criteria might be appropriate.

The recommended acceptance criterion is "If the computed UCL for a container is less than 0.5 wt\%, the threshold level specified in Department of Energy (DOE) Standard 3013-99 (DOE, 1999) then material is packaged; otherwise it is recycled". Since we selected $95 \%$ UCL criteria, this results in a $5 \%$ chance of packaging material with true moisture content right at the threshold level. The current criteria, which consist of recycling material if either LOI measurement exceeds $0.5 \mathrm{wt} \%$, has a $25 \%$ chance of packaging material whose moisture content is at the threshold. These packaging frequencies would also approximately apply for containers with moisture content slightly above the threshold value. Since the $25 \%$ chance of packaging this marginally non-compliant material of the current approach is considered to be excessive, the UCL approach is selected as a replacement method. Note that the $5 \%$ percent rate described could be modified to other target levels by changing the confidence level accordingly.

The $95 \%$ UCL criterion, using historical estimates of within can LOI variability and duplicate measurements for each container, reduces to requiring that a container LOI sample mean be less than $0.454 \mathrm{wt} \%$ to avoid recycle. We are then "95\% confident" that the true underlying moisture content is less than $0.5 \mathrm{wt} \%$, and the container is sealed as part of final packaging. Otherwise the material is recycled.

For the "excessive difference" criteria, if the difference in the two LOI measurements per container exceeds $0.111 \mathrm{wt} \%$, a review of the validity of the measurement results should be performed. This could lead to retest and resample, but it wouldn't be expected to require recycle 
unless the added evaluation indicated the need. About $5 \%$ of containers are expected to require such review due to observed "excessive differences". The criteria can be modified to reduce this rate if desired.

Los Alamos National Laboratory (LANL) data on Supercritical Fluid Extraction (SFE) studies on different material type were also analyzed. Generally the performance is considerably better than that of LOI testing, but it does depend on the material type. When SFE is implemented at PFP, consideration of the material type and the LANL results will be used to establish initial acceptance criteria until a sufficient data history is available to perform a more extensive analysis similar to that done for LOI.

Summary of specific recommendations:

- Change LOI moisture content acceptance criteria to use of $\mathrm{UCL}$

- Implement "excessive difference" criterion for the two LOI measurements per container

- For material streams demonstrating sufficient consistency, propose reducing frequency of container testing

- Evaluate sample moisture content homogeneity after blending process comes on line

- Use LANL study SFE results to establish initial SFE acceptance criteria based on material type to be processed

- Confirm applicability of LANL results through DQO application when sufficient SFE results become available

- Develop a procedure for evaluating performance and establishing DQOs for any new material streams 


\section{TABLE OF CONTENTS}

ABSTRACT 2

EXECUTIVE SUMMARY 3

TABLE OF CONTENTS . . . . . . . . . . . . . . . . . . . . 5

LIST OF ACRONYMS . . . . . . . . . . . . . . . . . . . . . . . . . . 6

1.0 INTRODUCTION . . . . . . . . . . . . . . . . . . . . . . . 7

1.1 PURPOSE OF THE DQO POCESS . . . . . . . . . . . . . . . . . 7

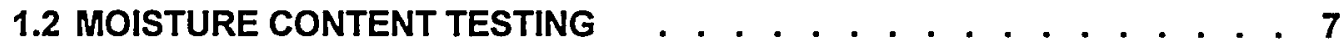

1.3 DQO APPLICATION TO LOI $\quad$. . . . . . . . . . . . . . . . 7

2.0 BACKGROUND ........................ 8

3.0 DQO STEP 1: STATE THE PROBLEM $\quad$. . . . . . . . . . . . . . . . . . 8

4.0 DQO STEP 2: IDENTIFY THE DECISION . . . . . . . . . . . . . . . . . 9

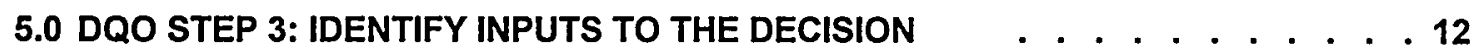

6.0 DQO STEP 4: DEFINE THE STUDY BOUNDARIES . . . . . . . . . . . . . . 14

7.0 DQO STEP 5: DEVELOP A DECISION RULE $\quad$. . . . . . . . . . . . . . 15

8.0 DQO STEP 6: SPECIFY LIMITS ON DECISION RULES $\quad$. . . . . . . . . . . . 16

9.0 DQO STEP 7: OPTIMIZE THE DESIGN FOR OBTAINING DATA $\quad$. . . . . . 18

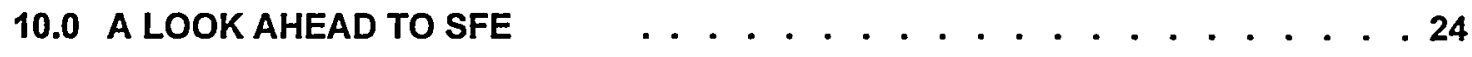

11.0 SUMMARY AND CONCLUSIONS . . . . . . . . . . . . . . . . 25

APPENDIX 1: DQO PROCESS . . . . . . . . . . . . . . . . . . 26

APPENDIX 2: TECHNICAL DERIVATIONS $\quad$. . . . . . . . . . . . . . 28

APPENDIX 3: REFERENCES . . . . . . . . . . . . . . . . 32 


\section{LIST OF ACRONYMS}

$\begin{array}{ll}\text { DOE } & \text { U. S. Department of Energy } \\ \text { DQO } & \text { Data Quality Objectives } \\ \text { EPA } & \text { Environmental Protection Agency } \\ \text { FH } & \text { Fluor Hanford, Inc. } \\ \text { IAEA } & \text { International Atomic Energy Agency } \\ \text { LANL } & \text { Los Alamos National Laboratory } \\ \text { LOI } & \text { Loss on Ignition } \\ \text { NDA } & \text { Non-Destructive Analysis } \\ \text { NM } & \text { Neutron Moderation } \\ \text { PFP } & \text { Plutonium Finishing Plant } \\ \text { PNNL } & \text { Pacific Northwest National Laboratory } \\ \text { PTH } & \text { Protection Technical Hanford } \\ \text { QA } & \text { Quality Assurance } \\ \text { SFE } & \text { Supercritical Fluid Extraction } \\ \text { UCL } & \text { Upper Confidence Limit }\end{array}$




\subsection{INTRODUCTION}

\subsection{PURPOSE OF THE DQO PROCESS}

The DQO process was developed by the U.S. Environmental Protection Agency (EPA 1987, 1994) to provide decision-makers with a tool for determining data requirements and their acceptable levels of confidence before sampling occurs. It assists in documenting the procedure used to determine the data requirements, making the data requirements more defensible. The DQO process can be applied to problems involving the collection and use of data and has been extended to the different issues associated with Hanford Site tank waste. The DQO process helps identify and define the type, quantity, and quality of data required. The process consists of seven steps:

- Step 1: State the problem

- Step 2: Identify the decision

- Step 3: Identify the inputs to the decision

- Step 4: Define the study boundaries

- Step 5: Develop a decision rule

- Step 6: Specify acceptable limits on decision errors

- Step 7: Optimize the design

A more detailed description of what each step entails is provided in Appendix 1. Sections 3.0 through 9.0 of this report address the seven steps of the DQO process in sequence.

\subsection{MOISTURE CONTENT TESTING}

DOE Standard 3013-99, Stabilization, Packaging, and Storage of Plutonium-Bearing Materials, (DOE, 1999) provides requirements that must be met prior to the packaging of stabilized nuclear material. Specific to our interest, this report includes the moisture content requirement listed as: "Stabilization Acceptance Criterion: The moisture content (weight loss, if using the LOI method) of Oxide to be packaged in any type of sealed container shall be less than 0.5 wt\% at the time of packaging."

Methods under consideration for such moisture content testing include LOI (Loss on Ignition), SFE (Supercritical Fluid Extraction), and NM (neutron moderation). LOI is currently in use at the PFP with preparations underway to switch to SFE. In the long term, NM may be the eventual test method.

Specific interpretation of the $0.5 \mathrm{wt} \%$ rule, or the data summary methods to be used to demonstrate the rule is met, have not been given. This report details the application of the DQO process to the sampling and LOI analyses activities used at the PFP. Implications for the changeover to the SFE method are also discussed.

\subsection{DQO APPLICATION TO LOI}

Generally the intent in using the DQO process is to thoroughly discuss the issues related to a particular application in order to establish an optimum sampling and analysis plan prior to the collection of data. In this application to LOI moisture testing, the process is already in use with an established performance history available. The primary goal of this DQO activity is therefore an evaluation of the current LOI sampling and analysis approaches, including the characterization of their performance with respect to potential decision errors and DOE Standard 3013-99 requirements. The need for process changes that improve that performance will then be evaluated. The results of applying the sequential DQO process steps are given in the successive sections in this report following some additional discussion of background information. 


\subsection{BACKGROUND}

The PFP has stabilized, and LOI tested for moisture content, two material types, sludge and product quality oxides (referred to as oxide in the remainder of this report). As might be expected, sludge with much higher pre-stabilization moisture content, proves to be the more difficult to treat and test. Treatment of additional sludge material is not expected, so this DQO activity is primarily directed at the testing of oxides. Historical LOI results for both material types are used in this report to evaluate the performance of the test and current data analysis methods. The more complex technical content of various topics is given in Appendix 2.

Currently, a sampled unit consists of a container of material. Each container is evaluated for moisture content using LOI prior to sealing. The testing of individual containers is the focus of this Phase 1 DQO application, so primary interest is in the moisture content and its uncertainty within each particular container. A follow-up Phase 2 activity could potentially be undertaken which would address process control and thus the related variation between containers, as well as within containers. The goal of such activity would be to demonstrate controlled treatment and analysis processes in order to reduce the sampling rate from every container to only some subset of containers.

Process improvements for sampling and analysis are planned for implementation in upcoming months. A blending step will be added to thoroughly mix a larger quantity of stabilized material that would then fill multiple containers. This blended batch would become the new sampling unit with test results then applied to each of the multiple containers filled with material from the blended batch. Some initial investigation of the homogeneity of moisture content within such a batch is recommended when the blending step is first added.

Also SFE testing will replace the LOI testing. When SFE capability is first realized, historical PFP SFE results, like those used in this report for LOI, will not be available. However, LANL studies, Rubin et al. (1999), provide some performance expectations through the use of multiple SFE tests on different spiked material types. Their data and results will be discussed in more detail later in this report and might prove useful in providing a starting point when SFE is first brought online at the PFP.

\subsection{DQO STEP 1: STATE THE PROBLEM}

Dwayne Speer, PFP manager, proposed that the following PFP participants join the PNNL participants to form the study team. These personnel participated, and their enthusiasm is appreciated.

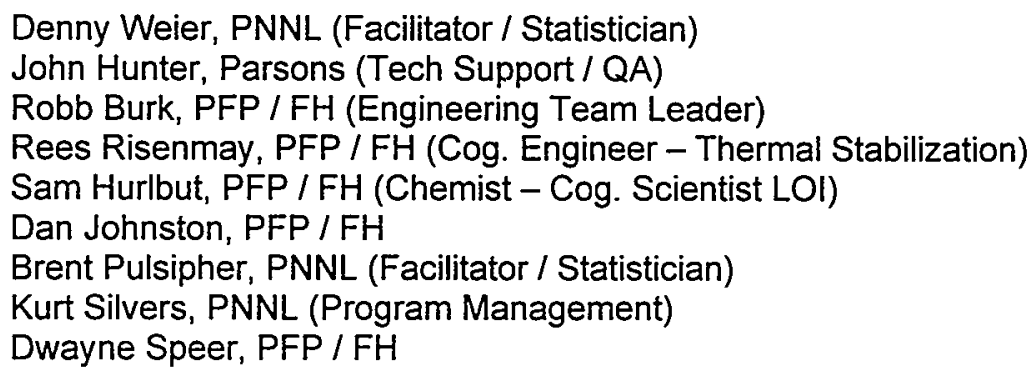

The team agreed that the decision-maker for this application is indeed Dwayne Speer. He possesses the ultimate responsibility for demonstrating that PFP stabilized material meets requirements. 
The problem of interest was formally stated as:

"To demonstrate moisture content of stabilized special nuclear material meets the 3013-99 moisture content requirement (< 0.5 wt\% at time of packaging)."

\subsection{DQO STEP 2: IDENTIFY THE DECISION}

The decision to be made was identified by the team as:

"Is the moisture content of stabilized special nuclear material, at the time of packaging into the container, less than $0.5 w t \%$ ?

\section{If yes, then package. \\ If no, then recycle."}

Discussion among the study team members revealed that when sample material is heated during the LOI testing process, sample moisture content is estimated as the weight loss between before and after the LOI test heating. However, historical data contain some negative losses, that is, weight gains. The explanation for these negative results is that moisture content loss in the sample material was exceeded by the weight gain realized in the heating process through the gain in oxygen through oxidation. While some of these gains are more substantial in the historical sludge results, for oxides they never fell outside the range 0.0 to 0.1 (resulting in negative losses from -0.1 to 0.0 ). Even though it is anticipated that the moisture content in such cases is minimal, the material that generates any negative loss is automatically recycled for additional treatment:

When discussion in this report turns to probabilistic modeling of the historical LOI moisture content measurements, negative results are omitted since they do not reflect the performance relative to moisture content. Rather they are taken to represent oxidation in the presence of minimal moisture loss, and they are thus omitted. To facilitate this DQO study, we assume that observed weight losses represent the true reduction in moisture content as intended, and any weight gains from oxidation that could potentially cancel out part of the weight losses, are by comparison insignificant.

The study team emphasized that they are not currently addressing the eventual repackaging of stabilized material into 3013 containers, but rather on the initial packaging of newly stabilized material that then awaits repackaging into 3013 containers and shipment. Final repackaging into 3013 containers may require additional moisture testing of the product currently being placed into interim storage containers. This DQO team is not considering such testing.

Note that each decision refers to an individual container. As briefly mentioned in the background information, a broader goal includes process control studies that would facilitate characterizing material streams and potentially alleviating the need for sampling and LOI / SFE testing of the material in every container. Also discussed in the background information was installing an inline blender that would be used to thoroughly mix a larger amount of material. Multiple containers would then be filled from the same batch of blended material. At that time the material represented by a sample will be the blender batch, and associated test results will be applied to each container filled from that batch. Neither the process control or blender topics are formally considered in this DQO activity.

A more detailed decision flow diagram for LOI testing that includes the recycle of any material with a negative LOI result is as follows: 
PNNL-13256

\section{Figure 4.1: LOI Decision Flow Chart}

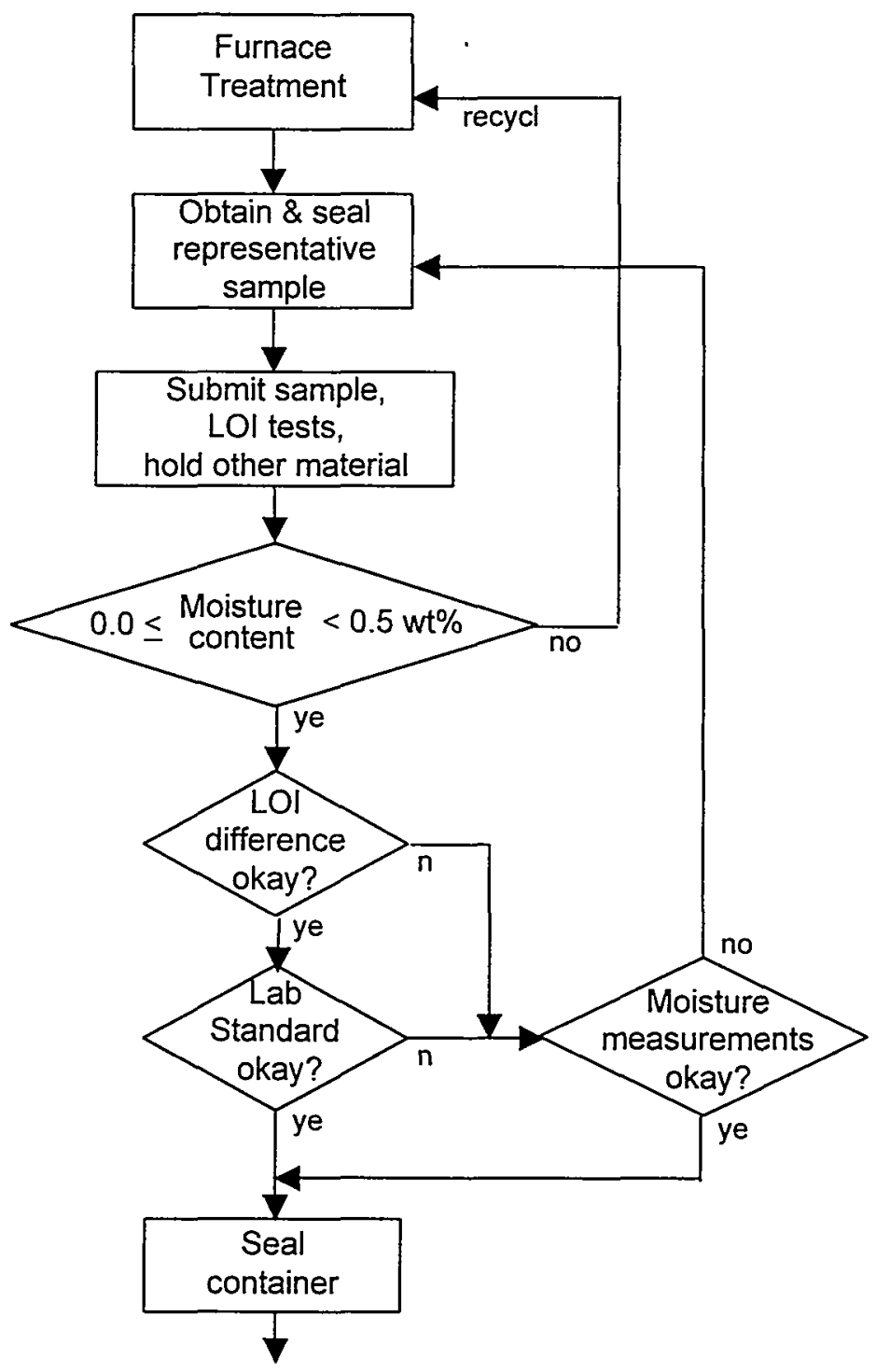

The decision point in this diagram that asks is the "LOl difference okay?" is based on comparing the two LOI results from a container and verifying that they are not "too far" apart. This will be discussed in more detail later in this report. It is recommended that failure to meet a "difference between samples" requirement would not require a recycle treatment, but rather a resample/retest, or some other re-evaluation of the LOI test results. Similarly, a quality control check that is currently done during LOI testing makes up the next decision point and could also require measurement re-evaluation or a resample retest.

An anticipated decision flowchart for SFE testing is given on the following page. The SFE testing dramatically shortens the time between the sample removal, sample testing, and permanent sealing. This can take several days for LOI testing, during which time the containers are temporarily sealed. Since SFE testing is done in line and requires much less time ( $\sim 1$ hour), the sample material can even be returned to the container prior to final sealing. 


\section{Figure 4.2: SFE Decision Flowchart}

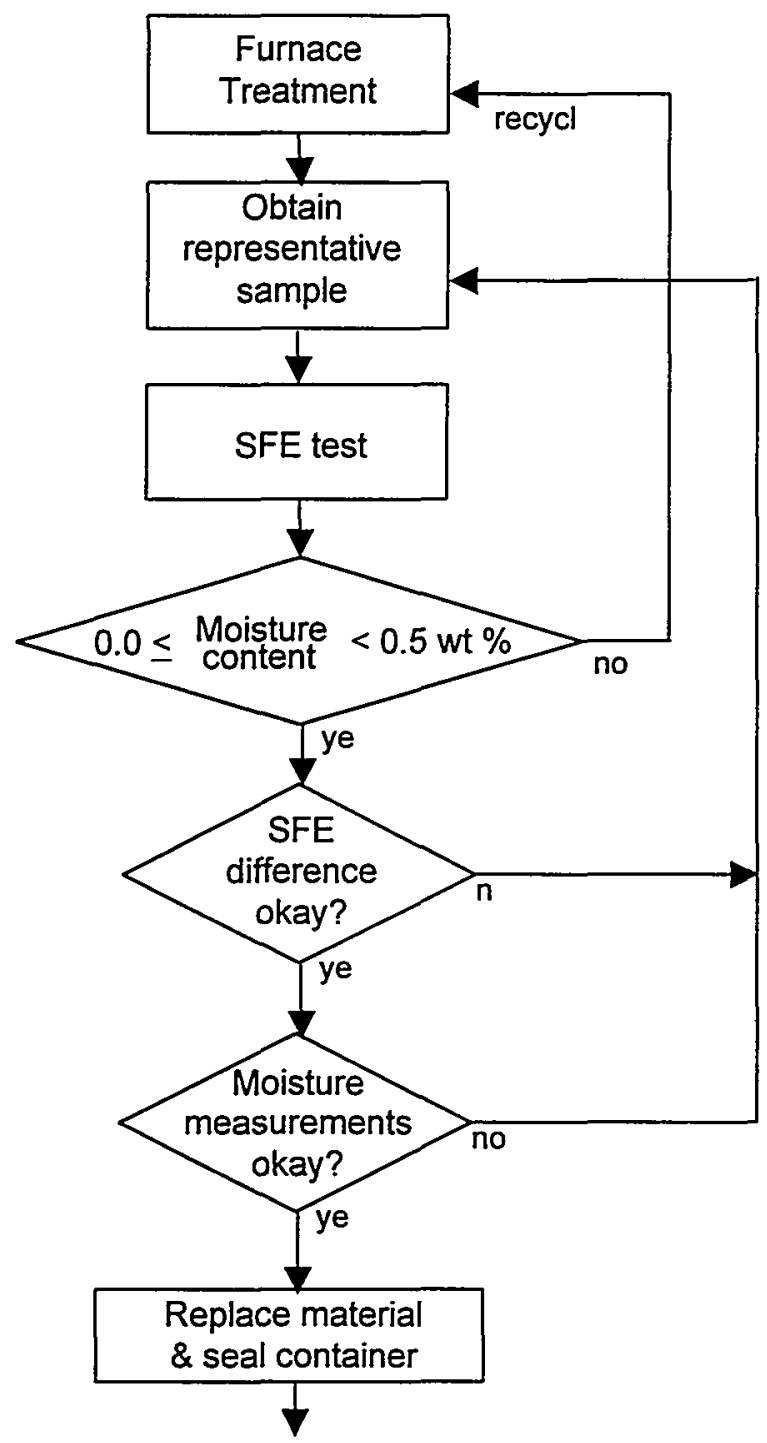

The decision point "Moisture measurements okay?" simply refers to quality assurance / quality control checks that confirm the SFE measurement system is performing as required. A similar issue that impacts the quality of LOI / SFE measurements is in regard to the quality control / quality assurance monitoring of the mass balances used for LOI / SFE. Any lack of compliance with quality control and calibration requirements for the balances can certainly affect the validity of the LOI / SFE tests. Consideration of such requirements for the balance(s) is not considered within the scope of this DQO activity. 


\subsection{DQO STEP 3: IDENTIFY INPUTS TO THE DECISION}

The inputs that influence the decision to be made were identified by the study team and are listed below. Discussion of the more important inputs follows the list.

- Type of material feed

- Furnace temperature

- Requirements from 3013-99

- Material sampling procedure

- Standard measurements taken during LOI

- Laboratory Measurements

Current - LOI on two 5 gram samples from cores

Eventual - SFE

- Historical record - data / performance

Sludge

Product quality oxide

To make probabilistic decisions regarding moisture content compliance, the variability between measurements of material from the same container will be needed. This variability likely depends on the type of material feed for both LOI and SFE. If so, the specifics of decision criteria would have to be developed for each type of material feed. Currently historical LOI data are only available for product quality oxide and sludge. The data used for this study are displayed on the following page.

Figure 5.1 gives historical results for oxide, Figure 5.2 for sludge, and Figure 5.3 gives the combined data. Data for five containers of oxide and six containers of sludge have been deleted from these figures and the subsequent analyses since they included at least one negative LOI result. This is thought due to weight gain caused by oxidation during the LOI testing process as discussed earlier.

Since the current testing procedure generates two measurements from the sample material taken from each container, the horizontal axis in each figure represents the mean of the two LOI results. The vertical axis in each figure represents the difference in the two LOI measurements. Thus each plotted point represents a container and indicates its mean moisture content as estimated by LOI (in the horizontal direction) and the difference in its two LOI measurements (in the vertical direction).

Note the shorter axis scales for the oxide figure. It would be contained within only the lower left portion of the sludge figure. In fact this is the case in the combined figure. The largest oxide mean results are seen to be near the designated threshold of $0.5 \mathrm{wt} \%$, while the sludge data has several larger mean results. In fact, data for two sludge containers with LOI results respectively about $16 \mathrm{wt} \%$ and $17 \mathrm{wt} \%$ were omitted from these figures since they distorted the horizontal scale too much. These data were however included in subsequent analyses.

The current decision criterion requires recycle if either of the two LOI measurements exceeds 0.5 $w t \%$. All the containers with LOI mean greater than $0.5 \mathrm{wt} \%$ were thus recycled since at least one of the measurements then had to exceed 0.5. None of these containers had mean less than 0.5 with one of the measurements greater than 0.5 , which certainly could occur. Thus for these containers, only those with mean greater than 0.5 were in fact recycled.

Note that the differences in the LOI means between containers are pertinent in process control applications. The more stability in the process, the more consistent would be the LOI means. Such information would be useful in arguing that not every container need be sampled. Clearly we could not make such an argument based on the sludge data, but we potentially could based on the oxide data. This is not the intent of the current DQO activity. Instead we are interested in 
Figure 5.1: Oxide

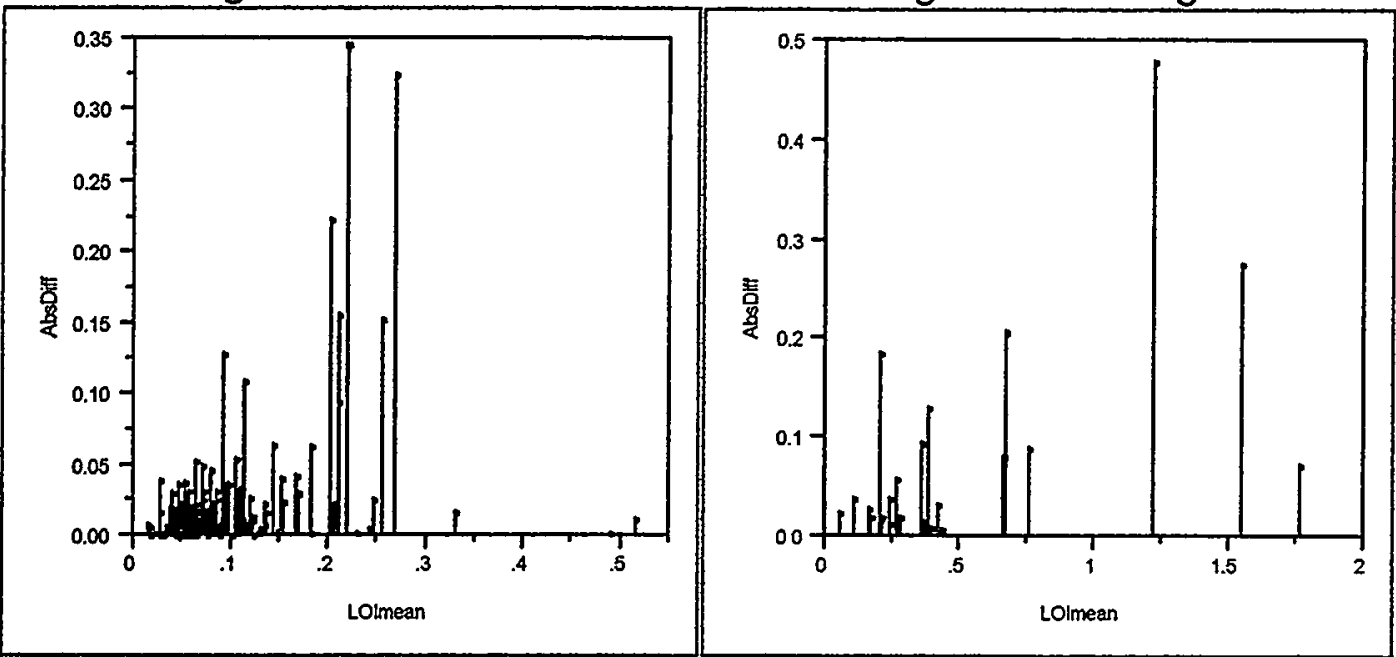

Figure 5.3: Combined

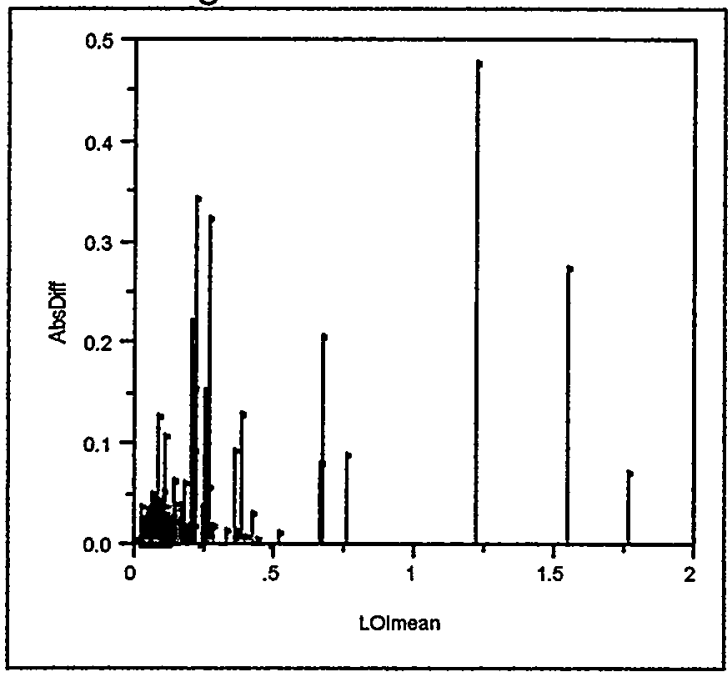

decisions within each container. Thus of more interest will be the variability observed between the two measurements made for the same container. Later analyses will address this topic. Of particular interest will be whether these data suggest the differences tend to be constant with respect to the mean moisture content, or whether they tend to increase as the moisture content increases.

Of particular importance is the representativeness of the sample material selected from a container. Reasonable decisions can only be made if the moisture content in this sample material accurately represents that of the entire container. The material sampling procedure was proposed by Terri Welsh, PTH (Protection Technical Hanford), to ensure a representative sample would be obtained for nuclear material accounting purposes. It was subsequently approved by the IAEA for material accounting. The procedure is contained in PFP Technical Operations Procedure Z0-160-034 (PFP, 2000).

The procedure includes using a container lid with randomly placed holes that allow core sampling. A coring tool is used in multiple holes in sequence until a required 11 grams of material is obtained. The material is bagged out and transferred to the laboratory for LOI 
measurement. Five grams of material are removed for the first LOI test, and a second five grams are then removed for the second LOI test. The remaining gram is archived for material accounting purposes since the primary material accounting measurement is based on NDA methods with the archived material providing and analytical backup if needed.

Sieving and shaking operations are used to mix the stabilized material prior to sampling. This helps to ensure the homogeneity of the moisture content. The approximately six vertical cores of stabilized material each reach from the top of the container to the bottom. Some mixing of the cores occurs as they are placed consecutively into a sample vial. This vial has substantial empty space inside after the 11 grams are added, so the material is further mixed as the vial is repeatedly handled through bag-out, bag-in, and laboratory operations. In fact, due to the nature of external packaging, the vial must be inverted during the bag-in operation.

Note that the DOE Standard 3013-99 does not state specifically how "moisture content" is to be characterized in order to demonstrate it meet the $0.5 \mathrm{wt} \%$ criteria. It could be based on the average moisture content in the container, or on some worst case result based on several samples. If the material is homogeneous with respect to moisture content, these quantities are theoretically the same. Even in the presence of non-homogeneity, a composite of representative sampled material would still provide a good estimate of the average moisture content.

We believe the initial sieving and shaking helps to ensure homogeneous material in the container. Then the core sampling process gives a good representation of the container, whether it is in fact homogeneous or not. These factors, and the subsequent mixing of the 11 grams of material in the handling of the vial, are believed to result in the two 5-gram samples having nearly the same moisture content that is indeed representative of the average moisture content in the sampled container.

The subsequent differences in the two LOI results are thus taken to primarily represent the uncertainty of the measurement process. The sampling and mixing steps are believed adequate to reduce sampling uncertainty to an insignificant level relative to this measurement uncertainty between the LOI results. Increasing this measurement uncertainty to compensate for sampling error is therefore considered unnecessary. Thus characterizing the variability between the test results for the two five gram samples is considered sufficient for estimating the uncertainty of the moisture content in the container. Historical data on sludge and product quality oxide are used for such estimation later in this report.

Note that such sampling issues will need to be revisited when the blender operation and the SFE in-line sampling and analysis are brought on line. A quantitative statistical evaluation of the adequacy of the mixing and sampling operations is recommended when the new systems are brought on line.

\subsection{DQO STEP 4: DEFINE THE STUDY BOUNDARIES}

The study team listed the study boundaries as:

- Plutonium / Uranium

- Material types:

$\begin{array}{ll}\text { Metal } & \text { Metal brushings } \\ \text { Product quality oxide } & \text { Alloy } \\ \text { Mixed oxide } & \text { Magnesium hydroxide precipitate } \\ \text { Sludge } & \text { Polycubes } \\ \text { Glovebox sweeps } & \\ \text { I / SFE / neutron moderation } & \\ \text { Personnel exposure } & \\ \text { me between sampling and sealing }\end{array}$


Of particular interest here is the difference in the following LOI and SFE timelines. The SFE implementation will provide significant improvement since the time from sampling to permanent sealing is reduced from several days for LOI to minutes for SFE.

Figure 6.1: LOI timeline:

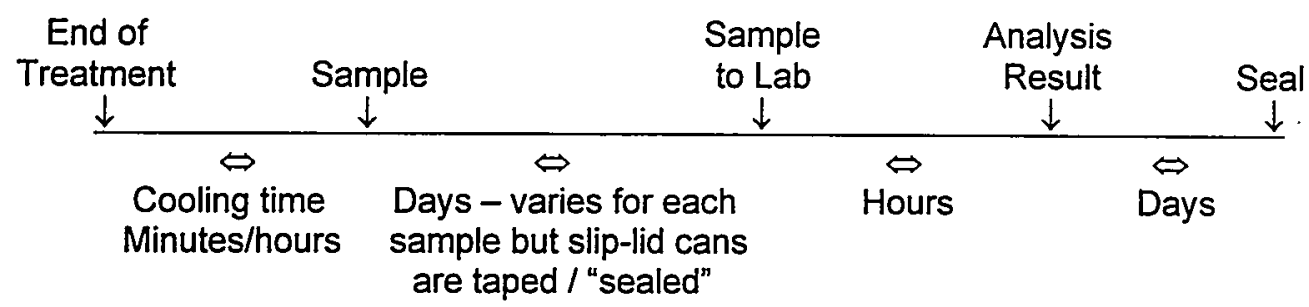

Figure 6.2: Expected SFE timeline:

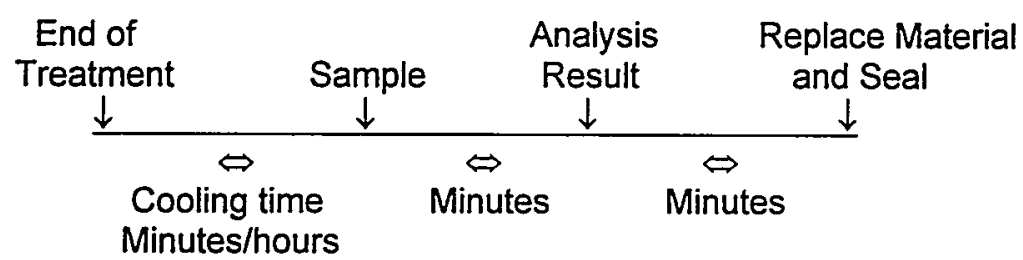

Note that among other restrictions, another limiting factor in the number of samples/analyses that might be obtained is personnel exposure. Also recall that for the current DQO applications, the decision criteria are being applied to each container individually. Future goals for material types with demonstrated consistency in achieved moisture content and its evaluation include reducing the sampling rate to consider only subsets of the containers.

\subsection{DQO STEP 5: DEVELOP A DECISION RULE}

As discussed, the DOE Standard 3013-99 requires "moisture content $<0.5$ wt\%". More specific guidance on how to demonstrate that material meets this requirement is not given. The decision now in place is:

Current decision rule: For $X_{1}$ and $X_{2}$ representing the two LOI results,

if both $X_{1}$ and $X_{2}<0.5 w t \%$, then package the material; otherwise recycle.

Alternatives for consideration include:

Alternative[1]: For $X$-bar $=\left(X_{1}+X_{2}\right) / 2$, the sample mean,

if $\mathrm{X}$-bar $<0.5 \mathrm{wt} \%$, then package the material; otherwise recycle.

Alternative[2]: For $S$ an estimate of the moisture content uncertainty within a container, $k$ an appropriate multiplying factor, and UCL representing the "upper confidence limit",

if $U C L=X-b a r+k S<0.5 w t \%$, then package the material; otherwise recycle. 
The relative merit of these decision rules is based on their protection against making decision errors. The two types of errors in this application are:

1. Determining that the moisture content of a container is less than $0.5 \mathrm{wt} \%$ when in reality it is greater than $0.5 \mathrm{wt} \%$. In this case we are packaging out-of-compliance material. We'll call this a "false acceptance" since we are accepting material for packaging that should have been rejected.

2. Determining that the moisture content of a container is greater than $0.5 \mathrm{wt} \%$ when in reality it is less than $0.5 \%$. Here we are recycling material unnecessarily. We'll call this a "false rejection" since we are rejecting material that should have been accepted.

The first of these error types, false acceptance, is considered to be more severe with potential impact on safety and contamination. The second error type, false rejection, impacts cost, personnel exposure, and schedule due to unnecessary recycle. We thus want a decision rule that will offer adequate protection against the false acceptance packaging while still doing a reasonable job in protecting against the false rejection recycling.

\subsection{DQO STEP 6: SPECIFY LIMITS ON DECISION RULES}

Step 6 of the DQO process generally requires that our willingness to tolerate these various types of error be specified as the true underlying moisture content ranges from being in compliance to out of compliance. In our application the sampling and analysis process is already in place, so our goal is to evaluate this approach with respect to decision error protection and to consider alternative approaches if needed. Consider the following foundation for a decision error curve:

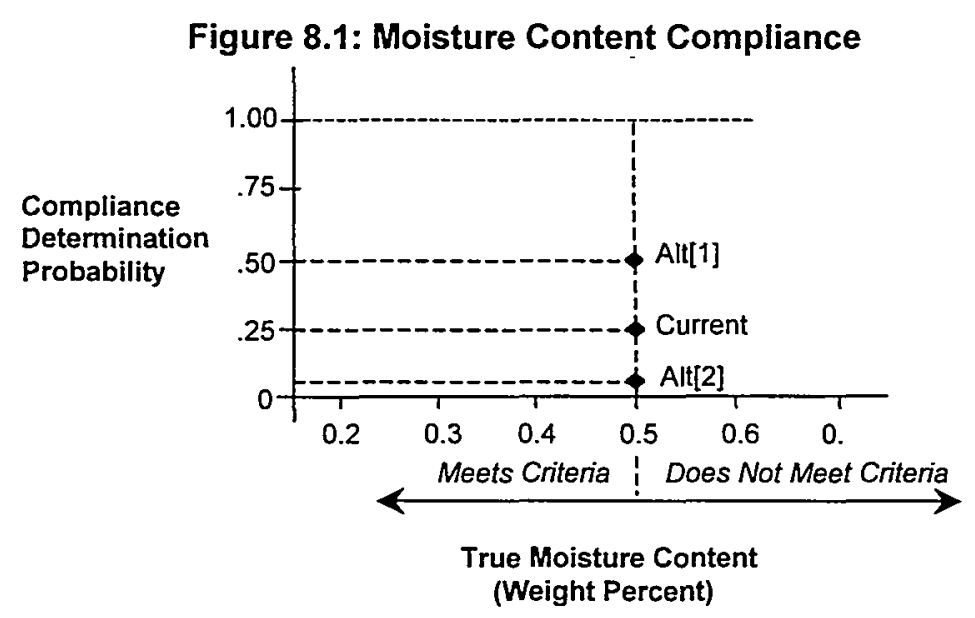

The horizontal axis on the curve represents the true, unknown, underlying moisture content for a container. The vertical axis represents the probability that we conclude that container is in compliance with respect to the $0.5 \mathrm{wt} \%$ threshold value based on our sample results. For containers that fall to the right of 0.5 on the horizontal axis, we hope to have a very low probability, close to zero on the vertical axis, of finding the container in compliance. Conversely, for containers that fall to the left of 0.5 , we hope to have a high probability, close to 1.0 on the vertical axis, of finding the container in compliance.

Probabilities of compliance determination for the three alternatives mentioned are easily derived when the underlying moisture content is precisely $0.5 \mathrm{wt} \%$. This is discussed in Appendix 2. 
Then the current approach, alternative[1], and alternative[2] have respective compliance determination probabilities of $0.25,0.50$, and 0.05 , as indicated by the diamonds on the figure. Note that for containers with moisture content only minimally above the threshold value, these compliance determination probabilities are nearly as large, and this then represents the probability of making a false acceptance decision, that is, packaging out of compliance material.

The rate of the current approach, 0.25 , is considered rather high. Twenty-five percent of containers with borderline moisture content are passed for packaging. Similarly, nearly that great a percentage would be packaged for moisture contents slightly above 0.05 wt\%. Alternative[1] performs even worse since it would accept for packaging $50 \%$ of such containers; it will therefore no longer be considered as a potential alternative.

Instead of the approach[1] comparison of the mean to the threshold limit, approach[2] requires a UCL for the mean to be less than the threshold limit in order to package the material. Selecting the particular confidence level determines the compliance determination rate in the borderline case. The 0.05 rate indicated on the figure is obtained by using a $95 \%$ UCL. This is considered a reasonable target rate to ensure that containers with moisture content slightly above $0.5 \mathrm{wt} \%$ have only a very small chance of being accepted for packaging.

The corresponding probabilities for other underlying moisture content levels are derived in Appendix 2 (for the constant standard deviation case). Those results are displayed on the next figure. Estimates of moisture content uncertainty are needed for these derivations. The uncertainty estimation approach is described briefly in DQO step 7 and in more detail in Appendix 2.

\section{Figure 8.2: Moisture Content Compliance}

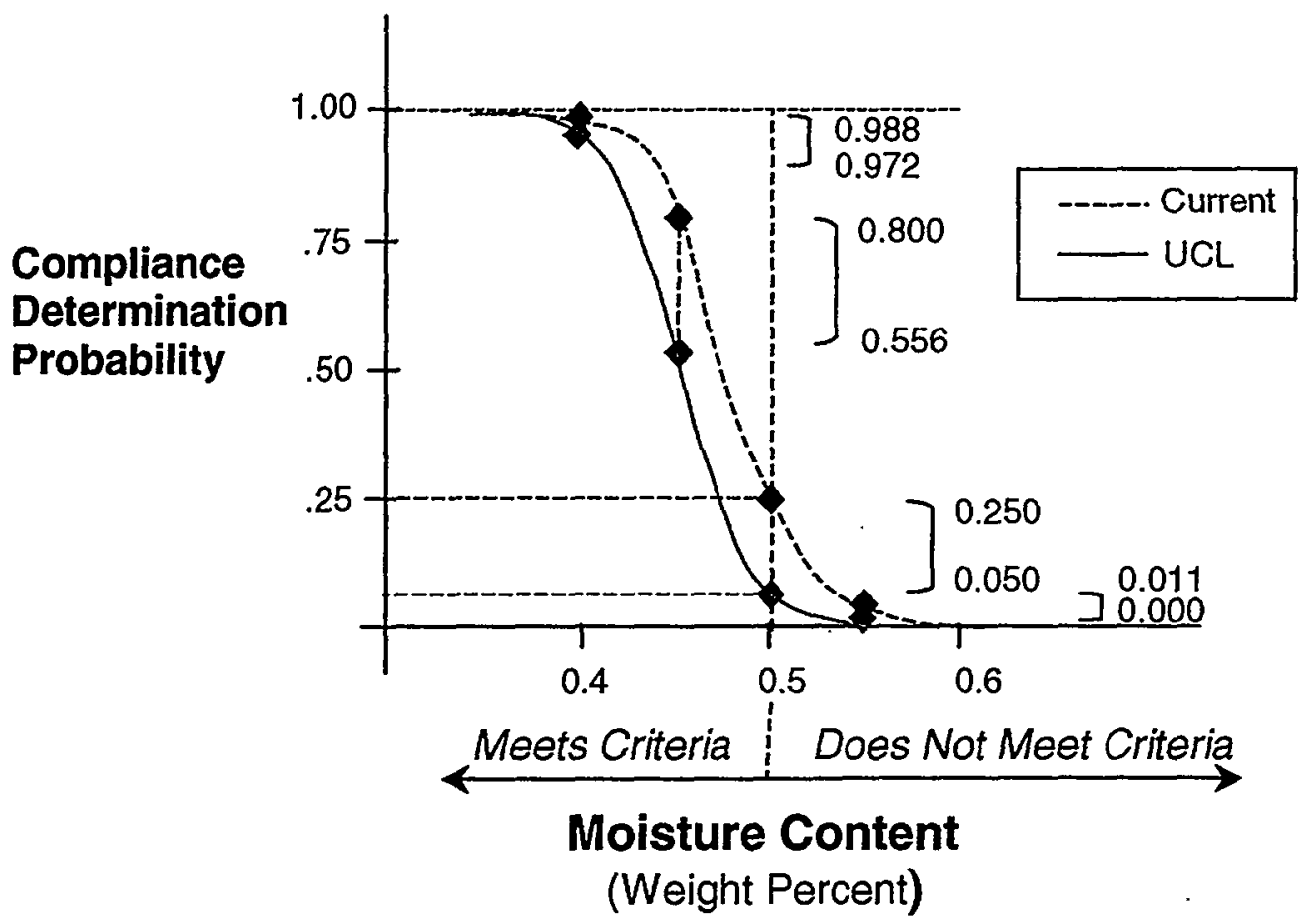

For each pair of probabilities listed to the right of the curves in Figure 8.2, the top probability is for the current approach, and the bottom probability is for the alternative UCL approach. The curves thus approximate such probabilities for all values of true underlying moisture content along the 
horizontal axis. The UCL approach results in much better protection against packaging material with moisture contents at or marginally exceeding the threshold value.

The curves use a standard deviation value for LOI test differences within containers based on the historical data. The value used is $0.04 \mathrm{wt} \%$, and it is appropriate for either sludge or oxide. The estimation process is described in Appendix 2 . Note that if this variability estimate were reduced, both curves in the figure would become steeper with the curve sections to the right of 0.5 becoming lower, and those sections to the left becoming higher. Thus more often correct decisions of both types would be made.

Another way to influence the curves is to change the sample size. These curves are based on the current container sample size of two. Say we increase this sample size to three, that is, we run three $L O I$ tests per container. The UCL curve by its definition would stay at probability 0.05 at $w t \%$ while lowering to the right and raising to the left. Thus correct decisions are made more often and both types of decision errors are more likely avoided.

The corresponding changes to the curve for the current approach show its biggest weakness. With three samples, the chance of any one of them exceeding 0.5 increases, so we are less likely to make a packaging decision. Thus the curve would lower across the entire range, and we would less often package non-compliant material (lower curve to the right), but we would also more often recycle compliant material unnecessarily (lower curve to the left). Increasing the amount of effort invested in measuring moisture content should help us make better decision for both compliant and non-compliant containers. However, increased testing with the current approach only increases the likelihood of unnecessary recycling of material.

Thus the UCL approach is accepted as an improvement over the current testing method. With it, any target acceptance probability can be specified for the borderline material by selecting the needed confidence level. An additional compliance determination requirement can then be specified for one other moisture content level, and adjusting the sample size can then attain that target as well.

Dwayne Speer, PFP manager, has indicated that the 0.05 rate for the borderline compliance case as used in our example discussion is appropriate. In addition the decision error protection then offered by a sample size of two with the UCL approach, as indicated in the curves above, is also acceptable. Details of this testing approach, as well as an additional condition on how different the two LOI results from a container can be, are discussed in the next section.

\subsection{DQO STEP 7: OPTIMIZE THE DESIGN FOR OBTAINING DATA}

A confidence interval approach was selected in the previous section. This was the alternative[2] approach discussed earlier. An upper confidence limit for the true underlying moisture content is compared to the 0.5 threshold value. This upper confidence limit $(\mathrm{UCL})$ is computed as:

$$
\mathrm{X}-\mathrm{bar}+\mathrm{kS}
$$

where $X$-bar is the average of the two LOI results, $S$ is an estimate of uncertainty for $X$-bar, and $k$ is an appropriate multiplying factor that reflects the combined uncertainty in X-bar and $S$. If we were to consider only a single container, our sample size would be two, and $S$ is then an extremely volatile estimator. Thus to compensate, $k$ has to be taken to be prohibitively large, as great as 5 or 6 . This would give very large UCLs and result in an excessive recycle decision rate.

To avoid this problem, we use the historical data and make a common assumption that the true underlying variability in LOI results is similar in each container. We thus pool the difference information given in Figures 5.1 to 5.3. to derive appropriate estimates $S$ and associated values $k$. Details are given in Appendix 2. That analysis indicates that the variability within containers is 
similar for oxide and sludge. Thus the data are combined to derive a single estimate of moisture content uncertainty.

Figures 5.1 to 5.3 provide some evidence that the differences may tend to be larger for higher moisture contents. This is not overwhelmingly the case, but it potentially could be a reasonable assumption. As a result, analyses were performed both for a constant standard deviation, which remains constant over all moisture contents, and for a relative standard deviation, which increases with increasing moisture content. When the associated analyses are performed, the constant standard deviation estimate obtained is $0.04 \mathrm{wt} \%$, while the relative standard deviation estimate obtained is $11.5 \%$ of the moisture content. Note that these approaches are approximately equivalent for a container with average moisture content of about $0.35 \mathrm{wt} \%$.

In either the constant or relative case, the $95 \%$ UCL is given by:

$$
X-b a r+1.645 S^{*} / \operatorname{sqrt}(2)
$$

where $S^{*}$, the standard deviation of moisture content within a container, is either $0.04 \mathrm{wt} \%$, or $11.5 \%$ of the estimated mean, $\mathrm{X}$-bar. This UCL generates a buffer area that forces $\mathrm{X}$-bar to be well less than $0.5 \mathrm{wt} \%$ in order for the UCL to be less than $0.5 \mathrm{wt} \%$. In Appendix 2 the UCL criteria are shown to be equivalent to;

$$
\text { Constant case: X-bar }<0.454 \text { wt } \% \quad \text { Relative case: } X \text {-bar }<0.441 \text { wt } \%
$$

Thus any container that does not meet whichever criterion is subsequently applied would be returned for recycle.

The two criteria will be compared in the following, but first, an additional criterion is suggested. If the two LOI measurements are "too different" from each other, review of the validity of the measurements should be required. This could lead to resampling and retesting, but not recycling unless the follow-up evaluation indicated the need.

Derivations of these difference criteria are discussed in Appendix 2. If we seek the same $95 \%$ confidence protection, we would flag larger differences that would be expected to occur only $5 \%$ of the time or less. Using the standard deviations above, this approach gives the following where the "Range" is the difference in the larger and smaller LOI test results for a container:

$$
\text { Constant: Range }>0.111 w t \% \text { Relative: Range }>0.323(X-b a r) w t \%
$$

All of the potential criteria are illustrated on Figures 9.1 through 9.4 on the following page. The axes on these figures respectively represent the two LOI measurements per container. The historical results for oxide and sludge are given on the associated figures. Each point on the figures represents the combination of the two LOI measurements the corresponding container generated.

In each figure, containers whose mean LOI result exceeds the associated criterion in equations 9.3 would fall above the slanted line in the area at the top right labeled "Recycle". Containers that fall outside the "Pass" regions that extend from the origin to the mean line at top right are considered too different according to the associated criterion in equations 9.4. (Discussion continues following the figures.) 
Figure 9.1: Oxide

Constant Standard Deviation

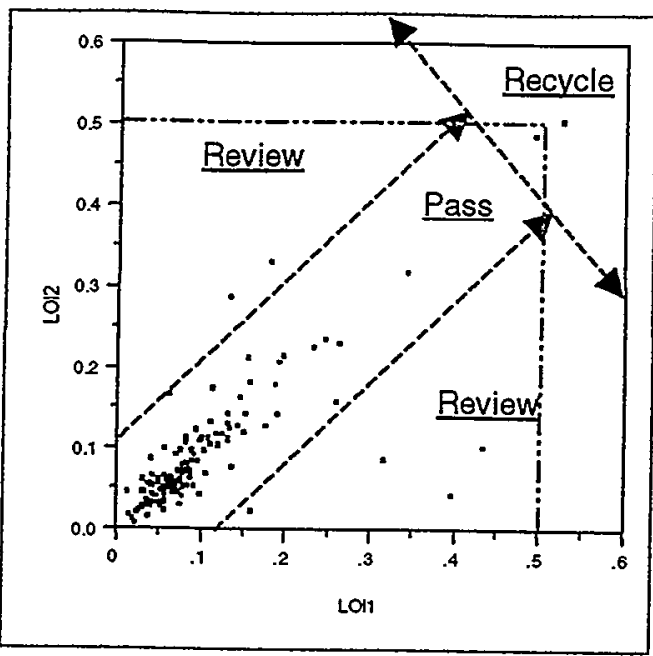

Figure 9.2: Oxide

Relative Standard DBNG

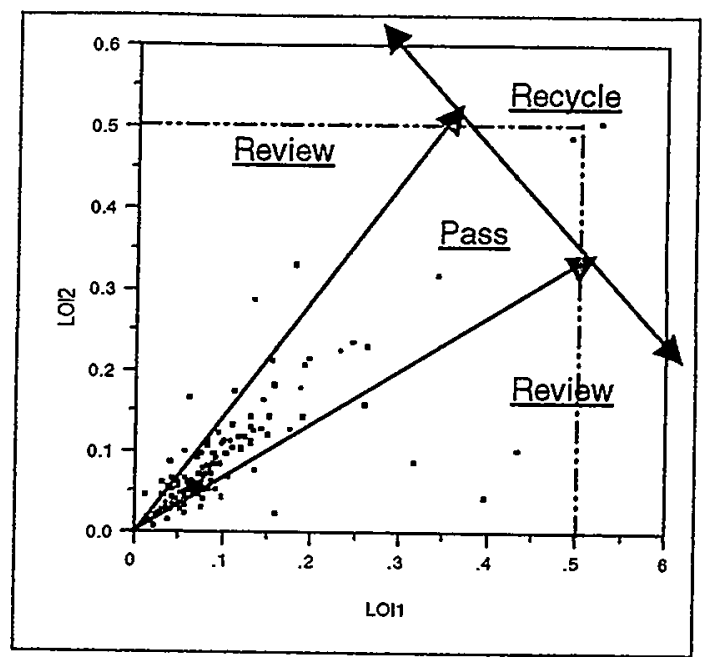

Figure 9.3: Oxide Standard Deviations

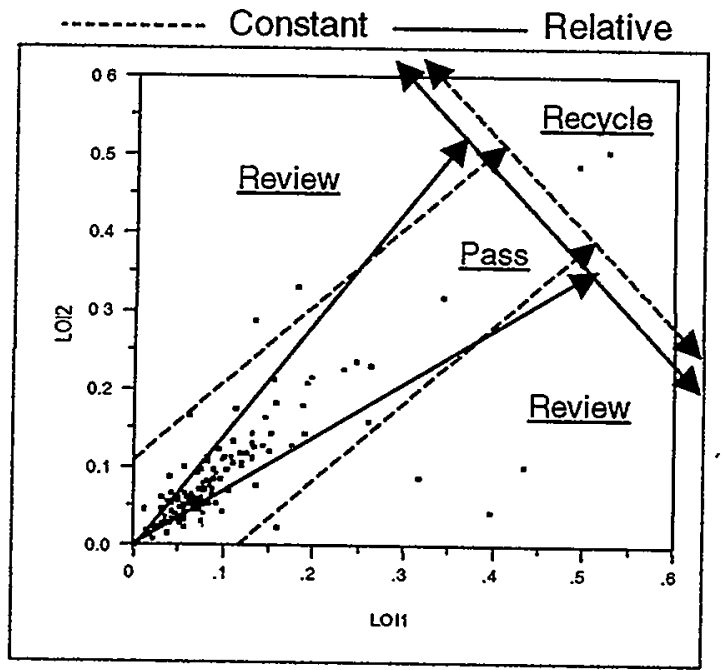

Figure 9.4 : Sludge

Constant Standard Deviation

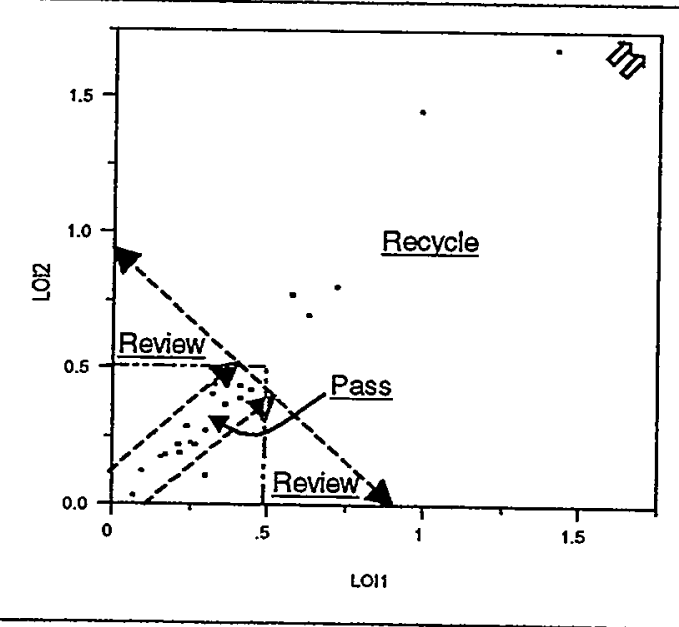


Possible outcomes therefore include:

1. A container falling in the "Pass" region, in which case it is accepted for packaging.

2. A container falling in the "Review" regions, in which case the two LOI measurements, with acceptable average moisture content, are sufficiently different that extra review is warranted. This could lead to resampling / retesting.

3. A container falling in the "Recycle" region, in which case the mean moisture content of the container was estimated to be sufficiently high that recycle is warranted.

Figures 9.1 and 9.2 respectively show the criteria for oxide for the constant standard deviation approach and the relative standard deviation approach. The red dot-dash lines indicate the current criteria for which any measurement greater than $0.5 \mathrm{wt} \%$ would generate a point outside the square dot-dash bounded area and thus require recycle. In both figures one container from the historical data would have been identified as requiring recycle under the new UCL criteria that did not require recycle under the current criterion. It had both measurements only slightly less than $0.5 \mathrm{wt} \%$, and the additional "conservatism" of the UCL approach would have required recycle.

Both Figures 9.1 and 9.2 show that more containers will be recycled with the UCL criterion than with the current approach. Indeed the extra recycle would be for those with measurements close to each other and close to $0.5 \mathrm{wt} \%$. This area is bordered by the triangle formed by the lines on Figures 9.1 and 9.2. The converse chance of a container requiring recycle with the current approach, but not the UCL approach, is very small. This is due to the small sample size. As was pointed out earlier in conjunction with the decision error curves, if the sample size increases to more than two, then the current approach would begin to recycle more material than the UCL approach.

Note the parallel lines that mark the "Pass" area in Figure 9.1. Outside these parallel lines is when we are concerned that the two LOI measurements are too different. The lines are parallel since we are assuming that the uncertainty within a container is the same for all average moisture contents. In contrast, the lines widen in Figure 9.2 under the assumption that we will have more variability in the LOI measurements when moisture content is higher. These lines result from the criteria in Equation 9.4.

The criteria of Figures 9.1 and 9.2 are combined in Figure 9.3. The difference in the two recycle areas is due to the 0.454 and 0.441 values in Equation 9.3. Deciding which of these two approaches should be preferred is somewhat difficult. The problem is we have little historical data in the 0.3 to 0.6 range where the difference in the approaches is most important. It is clear that we have more variability in the lower $\mathrm{LOI}$ results than is expected in the relative standard deviation case. That is why so many points fall outside the two converging lines as we approach the origin. This would require considerable effort in the "Review" of container results that are actually very far below the $0.5 \mathrm{wt} \%$ threshold, and this is not of practical importance. For this reason, the constant standard deviation approach of Figure 9.1 is recommended.

Note that about six oxide containers in the historical data are flagged for "Review" in this constant standard deviation approach. This is a reasonable result since we have derived the criteria so that about $5 \%$ of them should be. If this rate seems excessive, it could be reduced. If we instead want to target about $1 \%$ for review, the criteria would change from "Range $>0.111$ " to "Range $>$ 0.146 ". Then only three containers would have fallen into the "Review" areas.

Figure 9.4 gives the similar information for sludge which can be seen to have considerably more moisture and thus more frequent recycle. The criteria and performance are the same however for those containers with moisture content below the threshold level. The two arrows at the upper 
left represent the two containers that had moisture content at $16 \mathrm{wt} \%$ and $17 \mathrm{wt} \%$ and were thus recycled. Including them again interferes with the scale of the figure.

The following page is an example of a charting application that could be used to apply the derived criteria. It could be paper-based or computerized. It would provide an excellent historical performance record on which to base process control proposals to potentially reduce future sampling requirements for stable material types.

Container information and the LOI results are given in the top section of the chart. The LOI mean and difference are computed and then plotted on the charts. ' On the mean chart, any point plotted in the shaded area would require recycle of the associated container material. So too would any negative $\mathrm{LO}$ result. On the difference chart, points in the shaded area would require evaluation of the LOI test results to determine whether they are acceptable in spite of their large difference. Again this could lead to resample / retest, but not recycle unless evaluated indicated the need. 


\section{LOI Test Results}

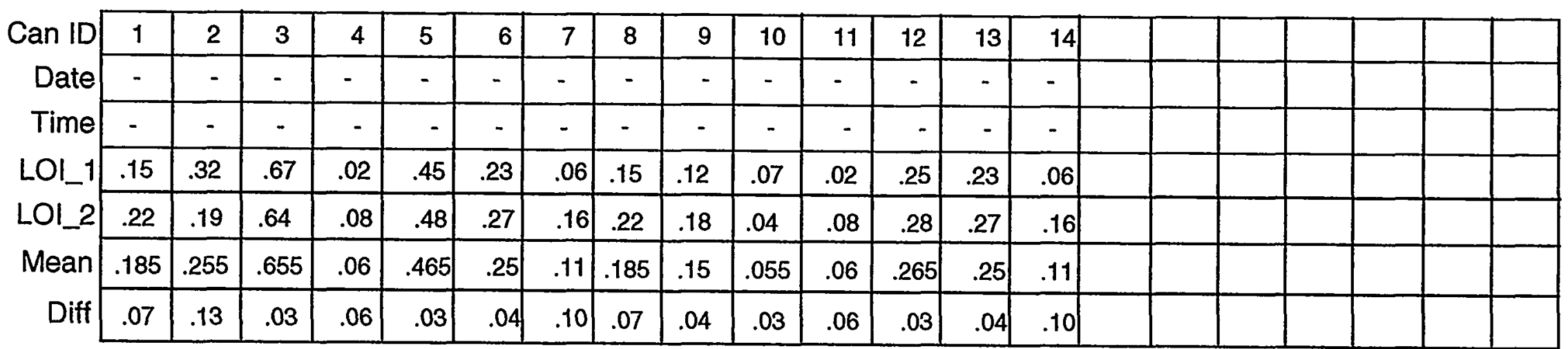

Either LOI measurement being negative requires recycle.

Plot of mean

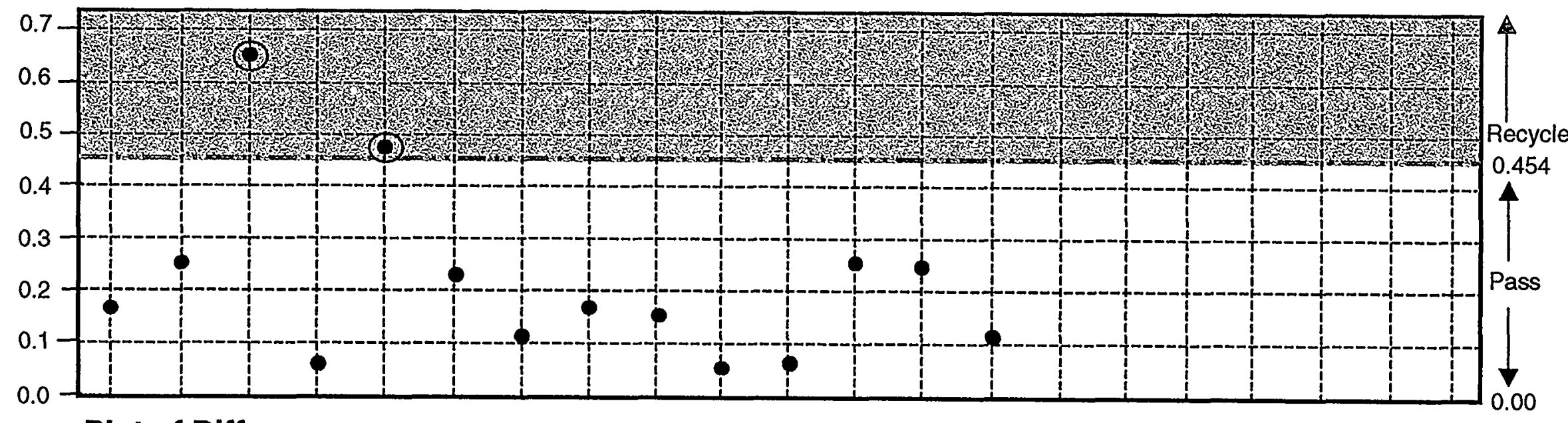

Plot of Difference

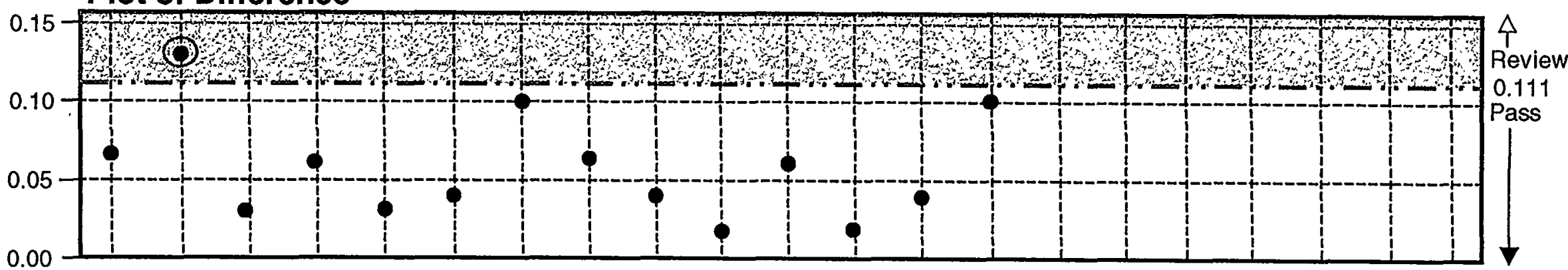




\subsection{A LOOK AHEAD TO SFE}

In review, we've selected a $95 \%$ UCL decision criteria for evaluating moisture content in order to identify those containers that require recycle. In addition, an "excessive difference" criterion is proposed that flags containers whose two LOI results are too far apart. The specifics of the criteria are based on the historical data and the within container standard deviation estimates that they give us.

When the SFE process initially replaces LOI, such historical information will not be available. What will be available are the results of the LANL study (Rubin et al. (1999)). Jim Rubin, a LANL chemist who worked on the SFE evaluation, has been contacted. He sent copies of the reports and data generated in a round robin study of LOI and SFE (among other methods) using different material types. The results below on "within container" SFE variability were generated using that data.

When SFE is first implemented, initial estimates of SFE measurement uncertainty can perhaps be based on these results. Then when sufficient SFE data are later available, results can be compared to confirm the initial estimates or determine the need for modification. Details of this type of "startup activity" for new material streams need additional discussion.

\section{LANL SFE Results (wt\%)}

\begin{tabular}{c|c|c|c|c} 
CASE & LEVEL & $\underline{N}$ & $\underline{\text { MEAN }}$ & $\underline{\text { STD }}$ \\
high chloride & spike 0.30 & 7 & 0.537 & 0.159 \\
& spike 0.70 & 7 & 1.191 & 0.322 \\
\hline \multirow{2}{*}{ high magnesium } & spike 0.16 & 7 & 0.157 & 0.010 \\
& spike 0.32 & 7 & 0.320 & 0.019 \\
& spike 0.52 & 7 & 0.491 & 0.041 \\
& spike 0.72 & 7 & 0.737 & 0.057 \\
\hline \multirow{2}{*}{ high plutonium } & spike 0.30 & 7 & 0.311 & 0.036 \\
& spike 0.70 & 7 & 0.670 & 0.032 \\
\hline \multirow{2}{*}{ high uranium } & spike 0.30 & 7 & 0.339 & 0.0157 \\
& spike 0.70 & 7 & 0.730 & 0.0163
\end{tabular}

The first column gives the material type. The pertinence of the results in each section will depend on which of these material types most closely resembles that to be measured when SFE is implemented. The second column is the spiked moisture level. The third column is the number of measurements made for each material batch. The fourth column is the mean of the seven measurements made in each case. Note that except for the high chloride material, the SFE results are extremely accurate since the mean values closely approximate the spiked values. For the high chloride material, the SFE appears to have about a $75 \%$ high bias.

The final column is the standard deviation of the seven measurements in each case. We appear to have a mix of constant standard deviation and relative standard deviation cases. For high uranium we see a constant standard deviation of about $0.016 \mathrm{wt} \%$ while high plutonium is 
constant at about 0.034 wt\%. Recall for LOl on oxide and sludge, we used a constant standard deviation of $0.040 w t \%$, so these SFE results are behaving more consistently.

For high magnesium we can see that a relative standard deviation of approximately $7 \%$ better reflects the uncertainty performance. The standard deviations clearly increase with the increasing moisture content. Recall the relative standard deviation for LOI that was considered was $11.5 \%$, so again we see the improved SFE performance.

For high chloride it again appears that a relative standard deviation is the more appropriate. It is about $50 \%$ of the spiked amount or $30 \%$ of the measured amount. Thus, relative to the $11.5 \%$ rate for LOI testing of oxide and sludge, SFE appears to have considerable difficulty in measuring moisture content of the high chloride material. It is biased 70 percent high and shows considerably more variability than for the other materials.

Consideration of the material type when PHP first implements SFE could facilitate the initial decision criteria. Similar criteria to those proposed for LOI could be used, but a reasonable estimate of the standard deviation is required.

\subsection{Summary and Conclusions}

In review, we've selected a 95\% UCL decision criteria for evaluating moisture content in order to identify those containers that require recycle. Since the variability within containers was observed in historical LOI data to be approximately the same for both sludge and oxide material, the same criteria could be used for either material. New material streams, and the conversion to SFE testing, will require similar investigation to determine what modification to the criteria might be appropriate.

If the computed UCL for a container is less than $0.5 \mathrm{wt} \%$, then material is packaged; otherwise it is recycled. Since we selected a $95 \%$ UCL criterion, this will result in a $5 \%$ chance of packaging material with true moisture content of $0.5 \mathrm{wt} \%$. The current criteria, which consisted of recycling material if either LOI measurement exceeds $0.5 \mathrm{wt} \%$ has a $25 \%$ chance of packaging such material. These packaging frequencies would also approximately apply for containers with moisture content slight above the threshold value $0.5 \mathrm{wt} \%$. Since the $25 \%$ chance of the current approach is then considered to be excessive, the UCL approach was selected. Note that the $5 \%$ percent rate described could be modified to other target levels by changing the confidence level accordingly.

The $95 \%$ UCL criteria, using historical estimates of within can LOI variability, result in the criteria that require a container LOl sample mean to be less than $0.454 \mathrm{wt} \%$ in order to be " $95 \%$ confident" that the underlying true moisture content is less than $0.5 w t \%$. Then the container is sealed as part of final packaging. Otherwise the material is recycled.

In addition an "excessive difference" criteria is proposed. If the difference in the two LOI measurements per container exceeds $0.111 \mathrm{wt} \%$, an evaluation of the validity of the measurement results should be performed. About $5 \%$ of containers are expected to require such evaluation due to "excessive differences". The criteria can be modified to reduce this rate if desired.

LANL data on SFE studies on different material type were analyzed. Generally the performance is considerably better than that of LOI testing, but it does depend on the material type. When SFE is implemented at PFP, consideration of the material type and the LANL results could be used initially until a sufficient data history is available to perform a more extensive analysis. 


\section{APPENDIX 1}

\section{DQO Process}

The basic structure of the DQO process consists of seven steps. The steps are sequential, and each step is dependent on the previous step. The seven steps are:

- Step 1: State the problem

- Step 2: Identify the decision

- Step 3: Identify the inputs to the decision

- Step 4: Define the study boundaries

- Step 5: Develop a decision rule

- Step 6: Specify acceptable limits on decision errors

- Step 7: Optimize the design

\section{Step 1: State the Problem}

The context of the problem is established by reviewing and summarizing existing information and describing the approach(es) under consideration to address the problem. During this step, the participants that should be involved in planning are identified and any practical constraints (limits of measurement technology, budgetary or time constraints) that might limit the approaches to problem resolution are recognized.

\section{Step 2: Identify the Decision}

A statement of the decision(s) that must be resolved based on data, including the possible decision outcomes (alternative courses of action) are identified. In addition, secondary data uses are specified.

Step 3: Identify the Inputs to the Decision

The information needed to make the decision is specified and the measurements that must be made to generate this information specified. Measurements needed to support secondary data uses should also be specified during this step. Typically the planning team iterates back to this step after attempting to specify the decision rule. At that point further focusing of the inputs to the decision frequently occurs. Any variables that are not included in the decision rule come under closer scrutiny. If a convincing argument cannot be made for its inclusion, the variable is dropped from the list of required measurements.

\section{Step 4: Define the Study Boundaries}

The spatial area or volume to which a decision will apply and within which data should be collected are defined. The planning team should consider whether representative (random) sampling is required or practical, and should define what population the data may represent and the decisions the data can be applied to. The smallest sub-population of tank waste or tank atmosphere for which a separate decision might be made should be specified. For example, if a separate decision will be made for each layer of material in the tank, data representative of each layer must be collected. Finally, some phenomena are variable over time within the tanks. The time frame for which a decision will be made should be specified. Also, for some measurements 
the time period over which samples or measurements should be taken in support of decision making should be specified.

\section{Step 5: Develop a Decision Rule}

The outputs from previous steps are integrated during this step into one or more statements that describe how data will be summarized and combined to form a result (mean, median, maximum, etc.) that will be used to determine the decision outcome. This step defines how the data generated from the study will be used. Typically the decision rule is stated as an "if... then..." statement that defines the conditions that would cause the decision maker to choose among alternative courses of action. The decision rule ignores the possibility of uncertainty in the data results (uncertainty is considered in Step 6).

\section{Step 6: Specify Acceptable Limits on Decision Errors}

The decision maker's (key data user's) acceptable decision error rates are defined in this step based on a careful consideration of the consequences of making incorrect decisions. By specifying decision error tolerances, the decision maker (data user) is accepting the fact that some probability of making an incorrect decision is inevitable because data can never perfectly reflect truth. The limits on decision errors drive many aspects of the design, including the number of samples and required precision and accuracy of the measurements. Iteration back to this step frequently occurs in order to balance the cost of collecting data against the uncertainty that can be accepted in the decision. It should be noted that although decision errors may be affected by analytical uncertainties, decision error tolerances are not the same as analytical error tolerances.

\section{Step 7: Optimize Design}

This step requires that the DQOs generated in the previous steps be carefully reviewed. The design team then translates the problem into a statistical framework, utilizes existing data and knowledge to specify the form of the underlying distribution and to estimate other key design parameters (e.g., the mean and variance of the underlying distribution and the cost of obtaining data), and generates alternative sampling designs. The most resource-efficient design that ensures an acceptable probability of making incorrect decisions is usually selected. If no design can be developed that meets all of the constraints specified (e.g., uncertainty limits and cost limits), then the planning team iterates back to earlier steps. Either a decision to relax or alter earlier DQO outputs is made, or a different approach may be selected (e.g., a decision may be made without data or with a different set of data).

The DQO process is meant to be iterative in nature. If measurements or decision error tolerances are deemed to be unattainable as one progresses through the DQO steps, reevaluating requirements outlined in earlier steps may be necessary. For some applications, sufficient progress through the first few steps may have been accomplished previously such that only documentation of the previous thought process cast in the context of the DQO logic may be needed before progressing through the remainder of the DQO steps. 


\section{APPENDIX 2}

\section{Technical Derivations}

Confidence interval Criteria: Historical data for LOI testing for approximately 150 oxide containers and 30 sludge containers were discussed in Section 5 . Of particular importance is estimating the variability between measurements from the same container in order to facilitate the $\mathrm{UCL}$ approach and to compute decision error probabilities for both the current and UCL approaches.

Using only the two measurements from a single container to estimate the variability for the container is not practical. Estimates of standard deviations for only two measurements are extremely volatile and can cover a very wide range of values. As a result, a UCL of the form

$$
\text { X-bar + k S }
$$

as discussed in conjunction with Equation 9.1 would require the value $k$ to be as large as 5 or 6 , whereas for larger numbers of measurements per containers, it would be in the range 1.5 to 2.0 . This would result in extremely large UCL's, and in requiring the UCL to be less than the threshold value $0.5 \mathrm{wt} \%$, we would recycle many containers that in fact have compliant underlying moisture content.

To avoid this situation we assume that variability within containers behaves similarly from one container to the next. We thus pool the information in the historical data to derive the best underlying standard deviation value estimate that could reasonably be expected to generate the types of differences observed between LOI measurements within containers. Those differences are shown in Figures 5.1 to 5.3. Note that the range of the two measurement is simply the absolute value of their difference, and then the sample standard deviation $S^{\star}=$ range / sqri(2). Thus plots of the computed sample standard deviations within each container versus the LOI mean for the container look just like Figures 5.1 to 5.3 with the vertical axis scale changed by the sqrt(2) factor. Recall that negative LOI results have been omitted for these figures and the related analysis.

Variability Estimates: The question was posed on whether these data better support a constant standard deviation that does not change with increasing moisture content, or a relative standard deviation that increases with increasing moisture content. One way to test this is to fit a regression line to the points on the standard deviation versus LOI mean plots (again like Figures 5.1 to 5.3). If this could reasonably be done with a resulting flat line, represented by a slope close to zero, the data could be taken to support a constant standard deviation relative to moisture content.

For both sludge and oxide, slopes statistically significantly greater than zero (approximately $0.115)$ are obtained in this way. This suggests that the standard deviation is relative and is about $11.5 \%$ of the estimated moisture content. A relative standard deviation approach is therefore to estimate the standard deviation within a particular container by using $11.5 \%$ of its estimated mean moisture content.

Alternatively, if one assumes a constant standard deviation within each container, one-way analysis of variance (ANOVA) can be used to estimate the between and within can variability. The within can variability would then be the root-mean-square-error of the ANOVA model. Such analyses led to:

\section{RMSE $\quad$ Degrees of Freedom}

$\begin{array}{lcc}\text { Sludge } & 0.046 & 17 \\ \text { Oxide } & 0.038 & 144\end{array}$


The degrees of freedom are reduced from the numbers of containers mentioned earlier due to the omission of those with negative results. If one tests the equality of the underlying standard deviations for oxide and sludge using the standard $F$-test, the results above would not be sufficient to conclude that they are different. A pooled estimate for both oxide and sludge is then the weighted quantity:

$$
S^{\star}=\operatorname{sqrt}\left\{\left[17(0.046)^{2}+144(0.038)^{2}\right] / 161\right\}
$$

which is approximately 0.04 . This is the quantity used in the constant standard deviation approach discussed earlier.

Given either the constant or relative standard deviation case, the $95 \%$ UCL is given by:

$$
X-b a r+1.645 \mathrm{~S} / \mathrm{sqrt}(2)
$$

where $S$ is either 0.04 , or $11.5 \%$ of the estimated mean, $X$-bar. This UCL generates a buffer area that forces $X$-bar to be less than $0.5 \mathrm{wt} \%$ in order for the UCL to be less than $0.5 \mathrm{wt} \%$. Equation 9.3 gave the following resulting criteria:

$$
\text { Constant: X-bar }<0.454 w t \% \quad \text { Relative: X-bar }<0.441 w t \%
$$

In the constant case, this is obtained by solving [X-bar $+1.645(0.04) /$ sqrt(2) ] $<0.5 \mathrm{wt} \%$ for $\mathrm{X}$-bar.

In the relative case, this is obtained by solving [ $X$-bar $+1.645(0.115 X$-bar) $/$ sqrt(2) $]<0.5 w t \%$ for X-bar.

As discussed earlier the relative and constant approach are for all practical purposes equivalent for containers with average moisture content around $0.35 \mathrm{wt} \%$. In the important area from .35 $w t \%$ to $.55 w t \%$, we have very little historical data so the decision on which approach is the more appropriate is difficult to justify. As indicated in the discussions of Figures 9.1 to 9.4 , the relative standard deviation approach leads to too many "excessive difference" warnings for containers with minimal moisture content for which we have little concern. Thus the final decision was made to adopt the constant standard deviation approach.

Normality Assumption: We assume a normal distribution of LOI measurements within containers to facilitate the derivation of decision error probabilities and to apply the UCL approach. If this assumption is valid, then the residuals from the ANOVA model described above should fit a normal distribution in the constant standard deviation case. In the relative standard deviation case, "relative residuals" after fitting a regression line to the LOI measurements plotted versus their means should similarly fit a normal distribution.

We have problems with the normal distribution fit in both cases. By having two measurements per container, we always get symmetric residuals since one is the negative distance to their mean, and the other is the corresponding positive distance. In both the relative and constant cases we see a few too many "large differences" than would be expected with normal distributions. Many of these large differences are coming from the low moisture containers in the relative case, and higher moisture range cases in the constant case. This is one reason why the relative standard deviation case might be preferred, that is, to compensate for the potentially larger standard deviations as the moisture content gets as large as $0.5 \mathrm{wt} \%$. But even if we use this relative approach, the difference is for $X$-bar exceeding $0.441 \mathrm{wt} \%$ instead of $0.454 \mathrm{wt} \%$ as shown in Equations 9.3. Only very rarely would this difference actually impact the decision made for a container. 
In spite of these "large difference" anomalies, we shall use normal distribution theory to approximate the various probabilities of interest. Note that for the UCL criteria, we do have the added benefit in subsequent containers of averaging the two LOI measurements. The smoothing that results from such averaging will help to alleviate the impact of the "large difference" anomalies in the UCL approach.

Decision Error Probabilities: The following compliance determination probabilities were computed for Figures 8.1 and 8.2:

True Mean Moisture Content

$0.40 w t \%$

$0.45 w t \%$

$0.50 w+\%$

$0.55 w t \%$
Current
Approach

0.988

0.800

0.250

0.011
$\mathrm{UCL}$ Approach

0.556

0.050

0.000

Example computations for the current approach are as follows:

1. For $0.5 w t \%, P($ both $X 1$ and $X 2<0.5 w t \% \mid$ true mean $=0.5 w t \%)=$ $\mathrm{P}(\mathrm{X} 1>0.5 \text { wt\% } \mid \text { true mean }=0.5)^{2}=(0.5)^{2}=\underline{0.25}$

2. For $0.4 w t \%, P($ both $X 1$ and $X 2<0.5 w t \% \mid$ true mean $=0.4 w t \%)=$ $P(X 1>0.5 \text { wt\% } \mid \text { true mean }=0.4)^{2}=P(Z<(0.5-0.4) / .04)^{2}=$ $P(Z<2.5)^{2}=(0.9938)^{2}=\underline{0.988}$

An example computation for the UCL approach is as follows:

1. For $0.4 w t \%, P(X$-bar $<0.454 w t \% \mid$ true mean $=0.4 w t \%)=$ $\mathrm{P}\{Z<(0.454-0.4) /[(.04) /$ sqrt $(2)]\}=\mathrm{P}(Z<1.91)=\underline{0.972}$

The other probabilities included in Figures 8.1 and 8.2 are computed similarly.

Difference Criteria: Criteria were given in Equation 9.4 that flag containers whose LOI measurements appear to be "too different". Such flagging would result in a review of the test results at a minimum, and potentially, a resample / retest requirement. The particular values derived were obtained as follows;

Constant Case: We need to find the number $k$ such that $P($ range $>k)=0.05$. Then containers with LOI difference greater than $k$ should occur less than $5 \%$ of the time and are therefore flagged for additional review.

$$
\begin{aligned}
& P(\text { range }>k)=P(X 1-X 2>k)+P(X 2-X 1>k)=0.05 \text {, but these latter two } \\
& \text { probabilities are equal, so we need } P(X 1-X 2>k)=0.025 \text {. But given } X 1 \text { and } X 2 \text { are } \\
& \text { assumed normal, } X 1-X 2 \text { will be normal with mean } 0.0 \text { and variance } \\
& \text { sqrt }\left[(0.04)^{2}+(0.04)^{2}\right]=0.566 \text {. Thus } P(X 1-X 2>k)=P(Z>k / 0.0566)=0.025 \text {. This } \\
& \text { implies } k / 0.0566=1.96 \text { or } k=0.111 \text {. }
\end{aligned}
$$

Thus the allowable difference in the constant standard deviation case is taken to be up to 0.111 . Any container with difference greater than this will be flagged. We expect about $5 \%$ of the containers to be flagged in this way and that is approximately what was observed for the oxide and sludge data in Figures 9.1, 9.3, and 9.4. 
Note that if a $1 \%$ flagging rate is targeted instead of a $5 \%$ rate, then 2.575 replaces 1.96 in the computation above, and the value $\mathrm{k}$ becomes 0.146 instead of 0.111 .

Relative Case: This derivation is somewhat more complicated since now we want to flag a container whose difference is too great relative to its mean moisture content. We thus get the requirement

$$
\begin{aligned}
& P(\text { range } / X \text {-bar }>k)=P[(X 1-X 2) / X \text {-bar }>k]+P[(X 2-X 1) / X \text {-bar }>k]=0.05 \text {, or } \\
& P[(X 1-X 2) / X \text {-bar }>k]=0.025 \text { as before. But } P[(X 1-X 2) / X-b a r>k]= \\
& P[(X 1-X 2)>(k / 2)(X 1+X 2)]=P[X 1(1-k / 2)-X 2(1+k / 2)] .
\end{aligned}
$$

This last expression involves a linear combination of assumed independent normal variables, so using the same approach as in the constant case, it is shown that $k=0.323$. Considerably more algebraic maneuvering is needed since the estimate of the standard deviation of the random variables involves $0.115 \mathrm{X}$-bar, but it is still relatively straight-forward. Thus any container with relative difference, range $/ X$-bar, greater than 0.323 , or equivalently with range $>0.323$ (X-bar), would be flagged for having too great a difference and require review of the test results and possibly resample and retest. A $5 \%$ rate would be expected, but as we saw earlier, an excessive number of low moisture content containers violate this condition. That is why the final recommendation is to go with the constant standard deviation approach.

If the slightly greater conservatism of the mean moisture content criteria based on the relative standard deviation ( that is, X-bar $<0.441 \mathrm{wt} \%$ instead of X-bar $<0.454 \mathrm{wt} \%$ ) is desired, then a modified relative standard deviation approach could be used. The difference criteria would need to be restricted to containers with moisture content greater than, say, $0.2 \mathrm{wt} \%$ to avoid the excessive flagging rate for low moisture containers. 
PNNL-13256

\section{APPENDIX 3}

\section{References}

DOE, 1999, Stabilization, Packaging, and Storage of Plutonium-Bearing Materials, DOE-STD-3013-99, U.S. Department of Energy, Washington. D.C.

EPA, 1987, Data Quality Objectives for Remedial Response Activities - Example Scenario: RI/FS Activities at a Site with Contaminated soils and Ground Water, PB90-272634, U.S. Environmental Protection Agency, Washington. D.C.

EPA, 1994, Guidance for the Data Quality Objectives Process, EPA QAVG-4, U.S. Environmental Protection Agency, Washington. D.C.

PFP, 2000, Plutonium Finishing Plant Technical Operations Procedure 20-160-034, Fluor Hanford, Inc., Richland, WA 


\section{Distribution}

No. of

Copies

OFFSITE

10

D.R. Speer

Plutonium Finishing Plant

Fluor Hanford
No. of

Copies

\section{ONSITE}

T5-50

19 Battelle Pacific Northwest Division

D.R. Weier (10)

$\mathrm{K} 5-12$

B.A. Pulsipher

$\mathrm{K} 5-12$

K.L. Silvers

K9-08

Information Release (7)

K1-06 